Proc. Indian Acad. Sci. (Chem. Sci.), Vol. 102, No. 5, October 1990, pp. 705-712.

(C) Printed in India.

\title{
Raman and infrared spectra of starch samples of sweet potato and cassava
}

\author{
N SANTHA, K G SUDHA, K P VIJAYAKUMARI, V U NAYAR* \\ and $\mathrm{S} N$ MOORTHY ${ }^{\dagger}$ \\ Department of Physics, University of Kerala, Kariavattom, Trivandrum 695 581, India \\ ${ }^{\dagger}$ Post-Harvest Technology Division, Central Tuber Crops Research Institute, Sreekariyam, \\ Trivandrum 695017, India
}

\begin{abstract}
Raman and infrared spectra of starch samples from sweet potato and different varieties of cassava (tapioca) are reported. Three regions of the spectra, the $\mathrm{OH}$ stretching region (3560-3000 $\left.\mathrm{cm}^{-1}\right)$, the $\mathrm{CH}$ stretching region $\left(3000-2800 \mathrm{~cm}^{-1}\right)$ and the finger print region (1600-200 $\left.\mathrm{cm}^{-1}\right)$, have been studied. The results are discussed in relation to the hydrogen bonding and the properties of starch samples.
\end{abstract}

Keywords. Vibrational spectra; starch; sweet potato; cassava; amylose; amylopectin.

\section{Introduction}

Raman spectra of D-glucose, cellobiose, maltose and dextran in solution in $\mathrm{H}_{2} \mathrm{O}$ and $\mathrm{D}_{2} \mathrm{O}$ (Spedding and Stamm 1942; Vasko et al 1971; Cael et al 1973; She et al 1974), of cellulose (Valonia ventricosa) (Blackwell et al 1970), of $\alpha$-lactose monohydrate and $\beta$-lactose in the crystalline state and of $\alpha$-lactose, $\beta$-lactose and equilibrated lactose in aqueous solution (Susi and Ard 1974) have been reported. The normal coordinate analysis of $\alpha$-D-glucose (Vasko et al 1972; Cael et al 1974) and Raman spectra of crystalline $\alpha$-D-glucose (Cael et al 1974) and D-fructose, L-sorbose and related compounds (Szarek et al 1984) have also been investigated. Cael et al (1973) have recorded and analysed the IR and Raman spectra of $V_{a}, V_{h}$ and B-forms of potato amylose. But no such investigation has been carried out on cassava starch which is a cheap source of food, feed and industrial material. In the present work, the infrared and Raman spectra of starch samples from four different varieties of cassava namely $\mathrm{M}-4, \mathrm{H}-165, \mathrm{H}-1687$ and $\mathrm{H}-2304$ are reported and analysed, as part of a detailed investigation on the structural differences between these varieties, and are compared with the spectra of sweet potato starch.

\section{Experimental}

All the samples were extracted by the standard procedure (Radley 1976). Fresh tubers were freed of skin and rind and disintegrated in a waring blender at low speed. Large

\footnotetext{
* For correspondence
} 
amounts of water were used. The starch milk so obtained was passed through a 260-mesh sieve to remove all fibrous impurities and allowed to settle for six hours. The supernatant water was drained off leaving the starch cake. The cake was dried in an oven at $50-60^{\circ}$ for 6 to $8 \mathrm{~h}$ and then powdered.

Raman spectra were recorded on a 1401 Spex Ramalog spectrometer with a Spectra Physics model 165 argon ion laser. Spectra were recorded taking the samples as pellets and rotating these at high speeds to avoid burning of the samples. The 541.5 and $488.0 \mathrm{~nm}$ lines of the laser with power ranging from $80-200 \mathrm{~mW}$ were used. The infrared spectra were recorded using a Perkin Elmer 983 spectrophotometer. All the spectra were recorded at room temperature $(300 \pm 3 \mathrm{~K})$.

\section{Results and discussion}

Three regions of the spectra have been studied: the $\mathrm{OH}$ stretching region, $3650-3000 \mathrm{~cm}^{-1}$, the $\mathrm{CH}$ stretching region, $3000-2800 \mathrm{~cm}^{-1}$, and the finger print region, below $1600 \mathrm{~cm}^{-1}$. The observed bands for both Raman (figures 1 and 2) and IR (figure 3) spectra are given in tables $1-3$.

In the $\mathrm{OH}$ stretching region seven bands are resolved for $\mathrm{M}-4, \mathrm{H}-1687$ and $\mathrm{H}-2304$ cassava samples. The band at $3263 \mathrm{~cm}^{-1}$ observed in the Raman spectrum of $\mathrm{H}-165$ is absent in other samples. The band near $3287 \mathrm{~cm}^{-1}$ found in the spectra of cassava samples is absent in the spectrum of sweet potato starch. But two additional lines appear at 3158 and $3515 \mathrm{~cm}^{-1}$ for sweet potato. Other lines in this region are more or less in agreement for all the samples studied. Infrared spectra of the $\mathrm{OH}$ stretching region of cassava and sweet potato samples show a very broad band, having a maximum at $3400 \mathrm{~cm}^{-1}$.

In the general theory of sweetness (Shallenberger and Acree 1967) it is pointed out that all compounds that taste sweet belong to an AH, B system and the initial chemistry of sweet taste must therefore be concerted intramolecular hydrogen bonding between the $\mathrm{AH}, \mathrm{B}$ unit of the sweet compound and a sterically commensurate $\mathrm{AH}$, $B$ unit of the receptor site. Also, a high frequency band which appears in the IR spectra of some sugar molecules has been empirically correlated to their sweetness (Shallenberger 1963; Birch 1976). The band observed at $3515 \mathrm{~cm}^{-1}$ in the Raman spectrum of sweet potato is significant in the reason that sweet potato is considerably sweeter than cassava. The intramolecular hydrogen bonding between the molecules of sweet potato starch and the receptor site appears to be stronger than that between the molecules of cassava starch and the receptor site.

$\mathrm{CH}$ stretching fundamentals are situated in a very narrow spectral region, a feature which causes an overlap of bands. M-4 and sweet potato have nine fundamental $\mathrm{CH}$ stretching nodes, while $\mathrm{H}-1687$ and $\mathrm{H}-2304$ have ten modes and $\mathrm{H}-165$ has eleven. Bands around 2990 and $2911 \mathrm{~cm}^{-1}$ observed in the spectra of cassava samples are absent in the spectrum of sweet potato starch. In the Raman spectrum of sweet potato, an additional band appears at $2942 \mathrm{~cm}^{-1}$.

Starch is a mixture of two molecular entities - a linear fraction, amylose, and its branched counterpart, amylopectin. In both the molecules, glucose in its $\left({ }^{4} \mathrm{C}_{1}\right)$ form (figure 4) is the building block or repeating unit. Cassava and sweet potato starch belong to the $C$ structure, having a lesser percentage of amylose (cassava $18 \%$ and sweet potato $20 \%$ ) compared to potato starch $(22 \%$ ) which has a B structure (Zobel 


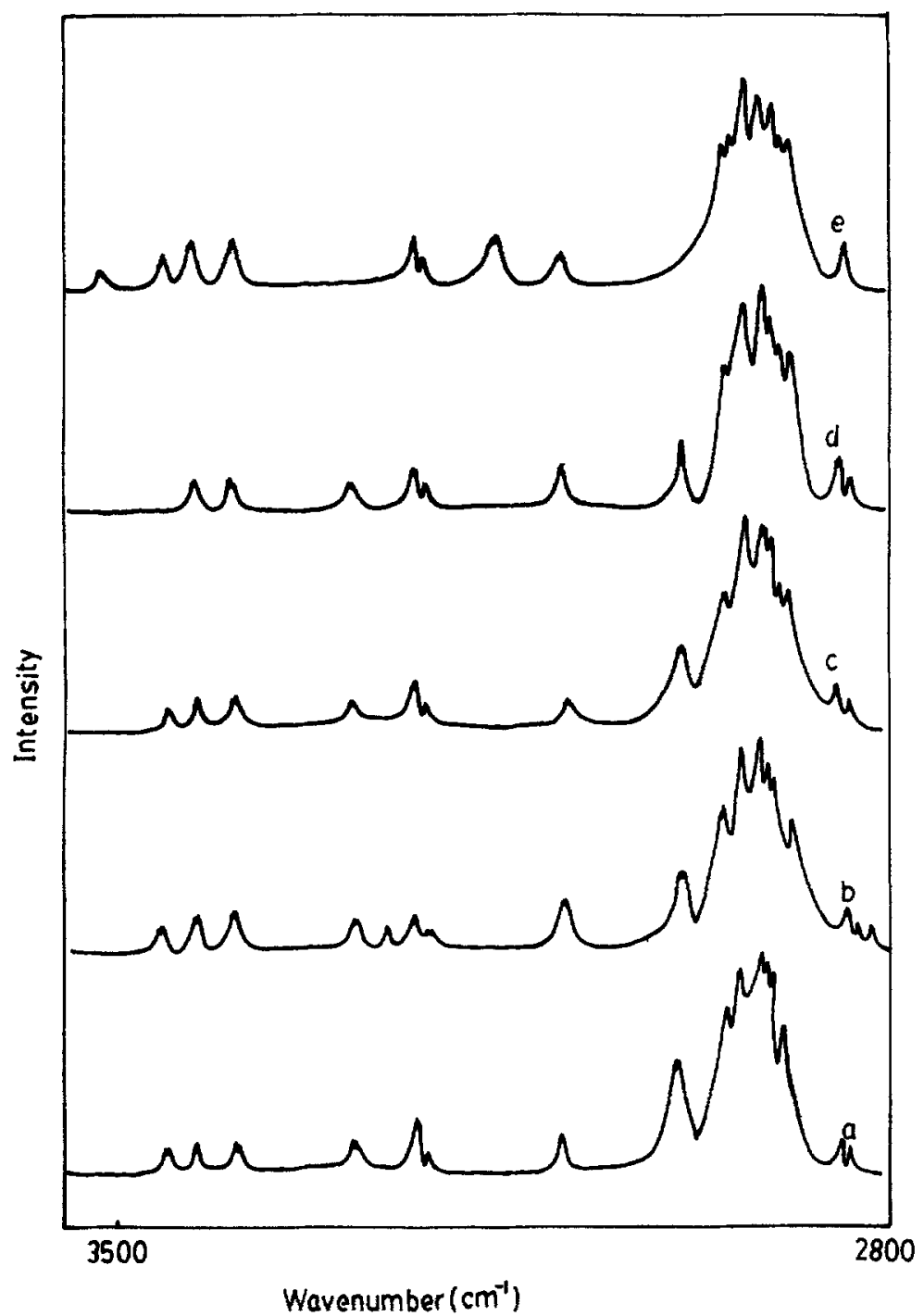

Figure 1. Raman spectra in the region $3600-2800 \mathrm{~cm}^{-1}$ of the starch samples of (a) $\mathrm{M}-4$, (b) H-165, (c) H-1687, (d) H-2304 and (e) sweet potato.

1988). Amylopectin content and crystallinity are greater in cassava and sweet potato starch than in potato starch. Amylopectin exhibits an $\alpha-1,4$ backbone and a $\alpha-1,6$ branch structure with relatively short $\alpha-1,4$ branches. $\alpha-1,6$ branching that occurs with the basic building block, $\alpha$-D-glucose, causes a shift in the $\mathrm{CH}$ stretching vibration. This leads to the absence of a $2940 \mathrm{~cm}^{-1} \mathrm{CH}_{2}$ stretching band, observed in the spectrum of potato amylose (Cael et al 1973, 1975), in the spectra of cassava samples. The $2940 \mathrm{~cm}^{-1}$ band is absent in the IR spectrum of the sweet potato sample. A very weak band is however observed in its Raman spectrum, probably due to the higher percentage of amylose in sweet potato starch as compared to that in cassava starch.

The observed spectra in the finger print region are similar to those of potato amylose. The $\mathrm{CH}_{2}$ twist and $\mathrm{C}-\mathrm{O}-\mathrm{H}$ bending modes at $1334 \mathrm{~cm}^{-1}$ observed in potato 

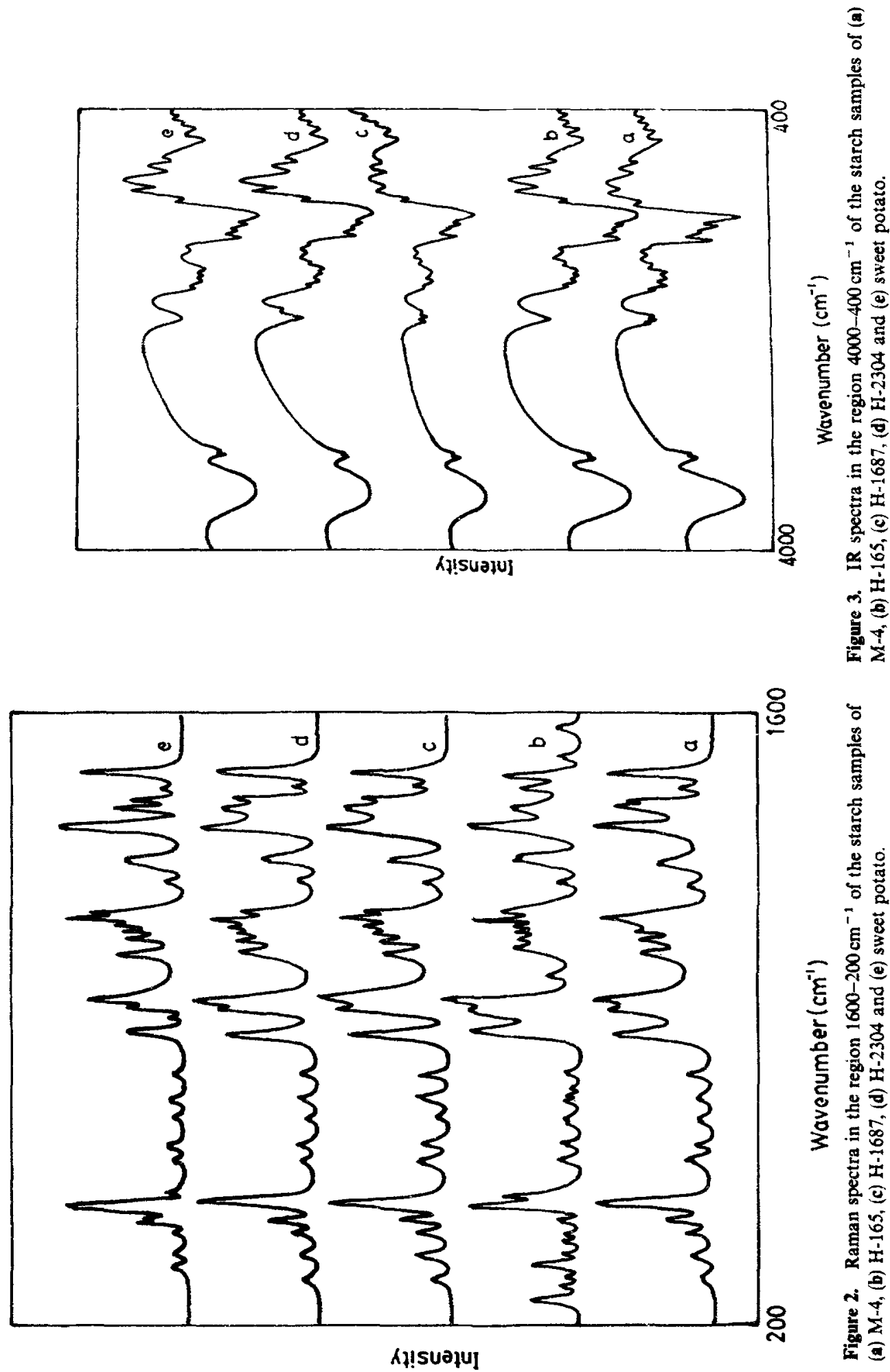

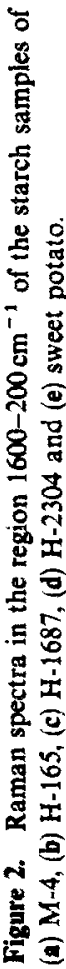


Table 1. Raman frequencies $\left(\mathrm{cm}^{-1}\right)$ of starch from cassava $\mathrm{M}-4$, $\mathrm{H}-165, \mathrm{H}-1687, \mathrm{H}-2304$ and sweet potato in the region 3600 $2800 \mathrm{~cm}^{-1}$

\begin{tabular}{lccccc}
\hline M-4 & H-165 & H-1687 & H-2304 & $\begin{array}{c}\text { Sweet } \\
\text { potato }\end{array}$ & Assignment \\
\hline & - & - & - & 3515 & \\
3455 & 3458 & 3455 & 3454 & 3460 & \\
3431 & 3430 & 3431 & 3431 & 3434 & \\
3393 & 3394 & 3395 & 3397 & 3397 & \\
3286 & 3285 & 3287 & 3287 & - & OH(stretching) \\
- & 3263 & - & - & - & \\
3230 & 3229 & 3229 & 3230 & 3230 & \\
3221 & 3220 & 3222 & 3223 & 3224 & \\
- & - & - & - & 3158 & \\
3097 & 3094 & 3093 & 3098 & 3099 & \\
2992 & 2987 & 2990 & 2990 & - & \\
2948 & 2951 & 2949 & 2949 & 2950 & \\
.- & - & - & - & 2942 & \\
2934 & 2933 & 2932 & 2933 & 2932 & \\
2915 & 2917 & 2914 & 2915 & 2917 & \\
2912 & 2910 & 2911 & 2911 & -- & CH(stretching) \\
2908 & 2904 & 2905 & 2905 & 2905 & \\
2895 & 2897 & 2898 & 2899 & 2899 & \\
-- & 2889 & 2891 & 2891 & 2891 & \\
2842 & $\ldots-$ & 2844 & 2845 & 2840 & \\
2838 & 2837 & 2838 & 2838 & 2838 & \\
- & 2830 & -- & $\ldots$ & -- & \\
.- & 2817 & - & - & - & \\
\hline & & & & & \\
\hline
\end{tabular}

Table 2. Raman frequencies (cm ${ }^{-1}$ ) of starch from cassava $\mathrm{M}-4, \mathrm{H}-165$, $\mathrm{H}-1687, \mathrm{H}-2304$ and sweet potato in the region $1600-200 \mathrm{~cm}^{-1}$.

\begin{tabular}{|c|c|c|c|c|c|}
\hline M-4 & $H-165$ & H-1687 & H-2304 & $\begin{array}{l}\text { Sweet } \\
\text { potato }\end{array}$ & Assignment \\
\hline- & 1564 & - & - & - & \\
\hline$\ldots$ & 1501 & -- & - & - & \\
\hline 1462 & 1454 & 1462 & 1463 & 1465 & $\mathrm{CH}_{2}$ (deformation) \\
\hline 1429 & 1430 & 1429 & 1429 & 1429 & \\
\hline 1401 & 1397 & 1403 & 1403 & 1402 & $\mathrm{CH}$ (bending) \\
\hline 1387 & 1384 & 1385 & 1385 & 1386 & \\
\hline 1340 & 1341 & 1342 & 1343 & 1344 & $\begin{array}{l}\mathrm{CH}_{2} \text { (twist), } \mathrm{C}-\mathrm{O}-\mathrm{H} \\
\text { (bending) }\end{array}$ \\
\hline 1261 & 1272 & 1263 & 1267 & 1267 & $\mathrm{CH}_{2} \mathrm{OH}$ (related mode) \\
\hline 1208 & 1213 & 1212 & 1215 & 1213 & \\
\hline 1148 & 1151 & 1147 & 1147 & 1147 & $\begin{array}{r}\mathrm{C}-\mathrm{O}, \mathrm{C}-\mathrm{C}, \mathrm{C}-\mathrm{H} \\
\text { (related modes) }\end{array}$ \\
\hline 1129 & 1124 & 1130 & 1131 & 1133 & \\
\hline 1113 & 1112 & 1115 & 1115 & 1123 & \\
\hline 1098 & 1100 & 1098 & 1098 & 1100 & \\
\hline 1085 & 1082 & 1085 & 1085 & 1089 & $\mathrm{C}-\mathrm{O}-\mathrm{H}$ (bending) \\
\hline 1057 & 1066 & 1054 & 1054 & 1056 & \\
\hline- & 997 & - & - & - & \\
\hline 943 & 943 & 943 & 943 & 943 & $\begin{array}{l}\text { Skeletal mode involving } \\
\alpha-(1 \rightarrow 4) \text { linkage }\end{array}$ \\
\hline
\end{tabular}


Table 2. (Continued)

\begin{tabular}{|c|c|c|c|c|c|}
\hline$M-4$ & H-165 & H-1687 & H-2304 & $\begin{array}{l}\text { Sweet } \\
\text { potato }\end{array}$ & Assignment \\
\hline 929 & 928 & 928 & 928 & 932 & $\mathrm{C}-\mathrm{O}-\mathrm{H}$ (bending) \\
\hline - & - & - & - & 906 & \\
\hline 870 & 874 & 866 & 866 & 873 & $\begin{array}{l}\mathrm{CH} \text { and } \mathrm{CH}_{2} \text { (deforma- } \\
\text { tion) }\end{array}$ \\
\hline 774 & 774 & 775 & 775 & 776 & \\
\hline- & 742 & - & - & - & \\
\hline 721 & 728 & 719 & 719 & 717 & \\
\hline- & 714 & - & - & - & \\
\hline 674 & 672 & 678 & 679 & 678 & \\
\hline 610 & 617 & 621 & 611 & 611 & \\
\hline 581 & 582 & 581 & 581 & 580 & \\
\hline 一 & 501 & - & - & 504 & \\
\hline 479 & 477 & 480 & 480 & 480 & Skeletal modes \\
\hline- & 451 & - & - & 450 & \\
\hline 442 & - & 443 & 440 & 443 & \\
\hline 412 & 412 & 413 & 412 & 414 & \\
\hline- & 397 & - & - & - & \\
\hline 360 & 363 & 363 & 362 & 364 & \\
\hline- & 340 & 一 & - & 337 & \\
\hline 308 & 313 & 308 & 305 & - & \\
\hline- & 290 & - & - & - & \\
\hline- & 257 & - & - & - & \\
\hline
\end{tabular}

Table 3. Infrared frequencies $\left(\mathrm{cm}^{-1}\right)$ of starch from cassava M-4, H-165, H-1687, H-2304 and sweet potato.

\begin{tabular}{rcccc}
\hline M-4 & H-165 & H-1687 & H-2304 & $\begin{array}{c}\text { Sweet } \\
\text { potato }\end{array}$ \\
\hline 3400 & 3400 & 3400 & 3400 & 3400 \\
2930 & 2930 & 2930 & 2930 & 2930 \\
2900 & 2900 & 2890 & 2890 & 2890 \\
1660 & - & 1655 & - & - \\
1637 & 1638 & 1632 & 1641 & 1637 \\
1600 & - & - & 1602 & - \\
1455 & 1440 & 1460 & 1457 & 1452 \\
1418 & 1418 & 1422 & 1415 & 1418 \\
1373 & 1370 & 1373 & 1372 & 1370 \\
1348 & 1345 & 1345 & 1342 & 1340 \\
1315 & 1310 & 1305 & 1305 & - \\
1242 & 1245 & 1245 & 1243 & 1240 \\
1160 & 1160 & 1160 & 1160 & 1155 \\
1105 & 1108 & 1105 & 1103 & 1100 \\
1080 & 1083 & 1082 & 1083 & 1080 \\
1022 & 1020 & 1025 & 1020 & 1015 \\
935 & 935 & 932 & 931 & 930 \\
862 & 862 & 862 & 862 & 863 \\
765 & 768 & 770 & 768 & 770 \\
710 & 710 & 715 & 715 & 712 \\
580 & 580 & 580 & 580 & 580 \\
530 & 530 & 530 & 530 & 532 \\
480 & 480 & 480 & 480 & 480 \\
440 & 440 & 440 & 440 & 440 \\
\hline
\end{tabular}




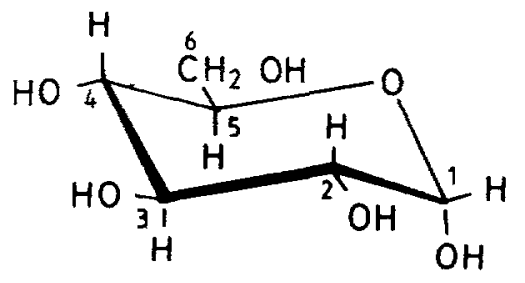

Figure 4. Structure of $\alpha-D$-glucose.

amylose and $\alpha$-D-glucose are observed near $1340 \mathrm{~cm}^{-1}$ in all the samples studied. The shift, though small, indicates $\alpha-1,6$ linkage in amylopectin in all the five samples. For D-glucose, cellobiose and maltose, Vasko et al (1971) assigned the band in the $1260-1280 \mathrm{~cm}^{-1}$ region to a mode involving the $\mathrm{CH}_{2} \mathrm{OH}$ side chain. For amylose, the line at $1263 \mathrm{~cm}^{-1}$ is probably due to a complex mode involving the $\mathrm{CH}_{2} \mathrm{OH}$ side chain in amylose (Cael et al 1973). All the samples studied showed a broad band near $1265 \mathrm{~cm}^{-1}$ and this could be assigned to the deformation mode of the $\mathrm{CH}_{2} \mathrm{OH}$ side chain of the amylose present in the starch samples. The broad band indicates the presence of additional modes within the contour as in $V$-amylose.

In potato amylose, the band near $946 \mathrm{~cm}^{-1}$ is assigned to the skeletal mode involving $\alpha-1,4$ linkage. In the present investigation also a band is observed at $943 \mathrm{~cm}^{-1}$ for all the samples, as such linkages are present in both amylopectin and amylose components.

The doublet at 861 and $840 \mathrm{~cm}^{-1}$ corresponding to $\mathrm{CH}$ and $\mathrm{CH}_{2}$ deformation modes observed in potato amylose (Cael et al 1975) is not found in cassava and sweet potato starch. Only one band around $870 \mathrm{~cm}^{-1}$ is observed in both the IR and Raman spectra of all the samples. Lack of crystalline perfection in the starch samples used for investigation, as compared to potato amylose, might have caused the decrease in the intensity of the lower band (Cael et al 1973).

The band near $1637 \mathrm{~cm}^{-1}$ in the IR spectra of the samples studied, has been attributed to the adsorbed water. This band is weaker, as the crystallinity of the sample increases. Cassava and sweet potato starch have the same crystallinity $(38 \%)$. For Valonia ventricosa, which is recognized as the most crystalline cellulose available, this band is barely visible (Liang and Marchessault 1959). This suggests that this band arises from the vibrations of adsorbed water molecules in the non-crystalline region.

Swelling volume and swelling power are two important properties of starch. Swelling volume is the volume of the gel formed when starch is allowed to swell freely in excess water and swelling power is the weight of the starch gel obtained from undissolved starch. H-165 has the highest swelling volume and swelling power $(37.8 \mathrm{ml} / \mathrm{g}$ starch, 51.8 respectively) among the four varieties of cassava investigated, $\mathrm{H}-1687$ being the lowest (25.5 ml $/ \mathrm{g}$ starch, 35.1 respectively) (Moorthy 1985). But the differences in the spectra are too obscure to reach any definite conclusion on swelling volume and swelling power.

\section{References}

Blackwell J, Vasko P D and Koenig J L 1970 J. Appl. Phys. 414375

Birch G G 1976 CRC Critical Rev. Food Sci. Nutr. 854

Cael J J, Koenig J L and Blackwell J 1973 Carbohydr. Res. 29123

Cael J J, Koenig J L and Blackwell J 1974 Carbohydr. Res. 3279 
Cael J J, Koenig J L and Blackwell J 1975 Biopolymers 141885

Liang C Y and Marchessault R H 1959 J. Polym. Sci. 39219

Moorthy S N 1985 Cassava starch and its modifications, technical bulletin series-4, Central Tuber Crops Research Institute, Trivandrum

Radley J A 1976 Starch production technology (London: Applied Science Publishers)

Shallenberger R S 1963 J. Food Sci. 28584

Shallenberger R S and Acree T E 1967 Nature (London) 216480

She C Y, Dinh N D and Tu A T 1974 Biochim. Biophys. Acta 372342

Spedding F H and Stamm R F 1942 J. Chem. Phys. 10176

Susi H and Ard J S 1974 Carbohydr. Res. 37351

Szarek W A, Korppi-Tommola, Shurvell H F, Smith W H Jr and Martin O R 1984 Can. J. Chem. 621512

Vasko P D, Blackwell J and Koenig J L 1971 Carbohydr. Res. 19297

Vasko P D, Blackwell J and Koenig J L 1972 Carbohydr. Res. 23407

Zobel H F 1988 Starke 4044 